\title{
Provision of clinical pharmacy services in two safety net provider settings
}

\author{
Sharon E. CONNOR, Margie E. SNYDER, Zachary J. SNYDER, Karen STEINMETZ PATER. \\ Received (first version): 19-Dec-2008 \\ Accepted: 16-Apr-2009
}

\begin{abstract}
${ }^{*}$
Objective: The purpose of this report is to characterize the patient population served by the Grace Lamsam Pharmacy Program and to describe program outcomes.

Methods: A chart review was conducted for all patients $(n=100)$ participating in the Grace Lamsam Pharmacy Program from January 1, 2007 to February 6,2008 . The primary outcome data collected were the medication related problems (unnecessary drug therapy, needs additional drug therapy, ineffective drug therapy, dosage too low, dosage too high, adverse drug reaction, noncompliance, and needs different drug product) identified by pharmacists, the number and type of pharmacist interventions made, estimated cost savings from perspective of the patient and clinical data (hemoglobin $\mathrm{A} 1 \mathrm{C}$, blood pressure measurements, and LDL-C) for patients with diabetes, hypertension, and hyperlipidemia, respectively. Basic demographic data was collected, including: patient gender, age, education level, race/ethnicity, marital status, and income. Patients' smoking status, type and number of medical conditions, medications being used at baseline, and number of pharmacist visits per patient during the study review period were also recorded. Results: The majority of patients cared for were male, middle-aged, and African-American. The majority $(90 \%)$ of patients had an income below $150 \%$ of the 2007 Federal poverty level. Patients were most commonly treated for diabetes, hypertension, and hyperlipidemia. During the period of review, 188 medication related problems were identified and documented with noncompliance being the most common medication related problem identified. Pharmacists completed 477

Pharmaceutical Manufacturer Assistance Program applications for 68 patients. These interventions represented a cost savings from the patients' perspective of approximately 243 USD per month during the review period. Blood pressure, $\mathrm{A} 1 \mathrm{C}$, and LDL-C readings improved in patients enrolled in the
\end{abstract}

*Sharon E. CONNOR. PharmD. Assistant Professor. University of Pittsburgh, School of Pharmacy. Pittsburgh, PA (United States).

Margie E. SNYDER. PharmD. Community Practice

Research Fellow, University of Pittsburgh, School of Pharmacy. Pittsburgh, PA (United States).

Zachary J. SNYDER. BS, PharmD Candidate 2011, Student Pharmacist. University of Pittsburgh, School of Pharmacy. Pittsburgh, PA (United States).

Karen STEINMETZ PATER. PharmD, BCPS, CDE.

Assistant Professor, University of Pittsburgh, School of Pharmacy. Pittsburgh, PA (United States). clinical pharmacy program at the free clinic and the community health center.

Conclusion: A clinical pharmacy services model provides a role for the pharmacist in an interdisciplinary team (beyond the traditional dispensing role) to identify medication related problems in the drug therapy of patients who utilize safety-net provider health care services.

Keywords: Poverty. Homeless Persons. Medication Therapy Management. Pharmacists. United States.

\section{PRESTACIÓN DE SERVICIOS CLÍNICOS EN DOS PROVEEDORES DE BENEFICENCIA}

\section{RESUMEN}

Objetivo: El propósito de este informe es caracterizar la población de pacientes servidos por el programa de farmacia Grace Lamsam y describir los resultados del programa.

Métodos: Se realizó una revisión de historiales de todos los pacientes $(n=100)$ que participaron en el programa de farmacia Grace Lamsam desde 1 de enero 2007 a 6 de febrero 2008. Los datos principales recopilados fueron los problemas relacionados con medicamentos identificados por los farmacéuticos (medicación innecesaria, necesidad de medicación adicional, tratamiento inefectivo, dosis muy baja, dosis muy alta, reacción adversa, incumplimiento, y necesidad de un producto diferente), número y tipo de intervenciones farmacéuticas realizadas, estimación de coste ahorrado desde la perspectiva del paciente y datos clínicos (hemoglobina A1C, presión arterial, y c-LDL) para pacientes con diabetes, hipertensión e hiperlipemia, respectivamente. Se recogieron los datos demográficos básicos, incluyendo género, edad, nivel educacional, raca/etnia, estado civil, e ingresos. También se registraron la situación de fumador, tipo y número de problemas de salud, medicamentos usados al inicio, y número de visitas al farmacéutico por paciente durante el estudio.

Resultados: La mayoría de los pacientes atendidos eran hombres, de mediana edad, y afro-americanos. La mayoría de los pacientes $(90 \%)$ tenían ingresos por debajo del $150 \%$ del Nivel Federal de Pobreza 2007. Los pacientes estaban habitualmente tratados de diabetes, hipertensión e hiperlipemia. Durante el periodo de revisión se identificaron y documentaron 188 problemas relacionados con medicamentos, siendo el incumplimiento el problema más comúnmente identificado. Los farmacéuticos completaron 477 solicitudes al 
Programa de Ayuda de Fabricantes Farmacéuticos para 68 pacientes. Estas intervenciones representaron un ahorro de coste desde la perspectiva del paciente de aproximadamente 243 USD por mes durante el periodo de revisión. Las lecturas de presión arterial, A1C y c-LDL mejoraron en los pacientes incluidos en el programa de farmacia clínica en la clínica gratuita y en el centro de salud comunitario.

Conclusión: Un modelo de servicios de farmacia clínica proporciona un papel para el farmacéutico en el equipo interdisciplinario (más allá del papel tradicional de dispensación) en la identificación de problemas relacionados con medicamentos en la farmacoterapia de pacientes que utilizan servicios sanitarios de proveedores de beneficencia.

Palabras clave: Pobreza. Personas sin hogar. Gestión de la medicación. Farmacéuticos. Estados Unidos.

\section{INTRODUCTION}

The overarching goals of Healthy People 2010 are the elimination of health disparities and the achievement of increased years of healthy life for the people of the United States. ${ }^{1}$ While these goals have been met for some of the population, medically underserved patients continue to suffer significant health disparities. ${ }^{2}$

Multiple factors influence the health of these individuals, including their access to medical care. Approximately $15 \%$ of Americans have no medical insurance, and $23 \%$ of non-elderly report they cannot fill a prescription because of cost. ${ }^{3-5}$ Low health literacy and lack of social support, along with inconsistent transportation also contribute to the lower health status of the medically underserved. ${ }^{6}$ Further, these individuals often suffer from a disproportionate number of medical problems, potentially placing these patients at risk for polypharmacy (i.e. multiple medications) and complex medication regimens, both of which may place patients at risk for medication related problems. $^{7,8}$ The complexity of these contributing factors demonstrates that managing drug therapy in the underserved population is difficult and traditional safety net services in the United States struggle to meet these needs. ${ }^{9}$ Evidence from the literature demonstrates positive outcomes when pharmacists provide pharmaceutical care to underserved populations. However, the majority of pharmacist services that have been described target specific chronic disease states, rather than the patient's entire medication regimen. ${ }^{10-13}$

The clinical pharmacy services described in this article are modeled after Medication Therapy Management (MTM) services and apply a comprehensive medication therapy review to optimize therapeutic outcomes for individual patients. ${ }^{14}$ This comprehensive, rather than disease specific, service offers a unique approach to addressing the medication related needs in the medically underserved. ${ }^{15,16}$

We describe the implementation of a clinical pharmacy service in a free medical clinic and a Community Health Center serving an urban population. The clinical pharmacy service was designed to facilitate improved access to prescription drugs, while working with patients and other providers to coordinate care and resolve medication related problems. The purpose of this review was to characterize the patient population, assess outcomes and to collect data to assist in refining the service in the future.

\section{Development and expansion of the clinical pharmacy service}

The Grace Lamsam Pharmacy Program was established in 1995 by faculty members at the University of Pittsburgh School of Pharmacy. The program consists of volunteer pharmacists and students from the Pittsburgh area who provide pharmacy services at the Birmingham Free Clinic (BFC), which is a free primary health care clinic. The BFC clinic serves primarily homeless and lowincome people. Pharmacists work in an interdisciplinary model of care with a team of healthcare providers that includes physicians, nurses, and other allied-health professionals. The Grace Lamsam Pharmacy Program initially provided volunteer pharmacists solely to enhance access to cost-effective medicines for patients. Over time this access has primarily been achieved through Pharmaceutical Manufacturer Assistance Programs (PMAPs) offered by drug manufacturers. PMAPs are generally sponsored by pharmaceutical companies and provide free or discounted medications to low-income, uninsured, and underinsured people who meet certain eligibility criteria.

The Grace Lamsam Pharmacy Program was expanded to the North Side Christian Health Center (NSCHC), a Community Health Center, in the fall of 2003. At this clinic, patients were referred to a pharmacist if they were having problems paying for their medications. The pharmacist-managed service was designed to screen patients for eligibility for PMAPs. Pharmacists also evaluated drug therapy for appropriateness and made recommendations as necessary to ensure the best medication related outcomes for the patients; however these activities were not standardized or documented consistently at that time.

In January 2007, the Grace Lamsam Pharmacy Program was further enhanced to include a more formal clinical pharmacy service which was implemented at BFC and $\mathrm{NSCHC}$. The service allowed for pharmacists to provide comprehensive pharmacy care for all patients in need, regardless of insurance status and need for PMAP consideration. The extent of clinical pharmacy services was modeled after a Medication Therapy Management (MTM) design developed by the University of Pittsburgh School of Pharmacy and in use at other School community partner sites. Doing so allowed volunteer pharmacists and students the opportunity 
to expand their knowledge of the MTM model to a unique patient population.

Through this approach to clinical pharmacy services, patients meet face-to-face with a pharmacist who has participated in a specialized, two day MTM training session with University of Pittsburgh School of Pharmacy faculty. After each patient encounter, the pharmacist enters patient information into the custom-designed computer software program. The software stores the information for future reference (similar to an electronic medical record) and facilitates the preparation of a printed personal medication record (PMR) and individualized recommendations for selfmonitoring (i.e. the Medication Action Plan). Further, it enables continuity of pharmaceutical care for patients served by BFC and NSCHC and facilitates the evaluation of clinical outcomes. Specific activities performed by volunteer pharmacists are dependent on the needs of the patient. For example, when appropriate for a patient, the PMR and medication action plan are provided. In some cases, the primary need of the patient is still drug product provision, so while the pharmacist will review the medications, the emphasis of the visit is on ensuring access to medications through various resources including PMAPs.

\section{METHODS}

\section{Data Collection}

A chart review was conducted for all patients $(n=100)$ that participated in the Grace Lamsam Pharmacy Program from January 1, 2007 (when the clinical pharmacy service was implemented) to February 6, 2008 (when the quality improvement initiative was evaluated). This retrospective review was approved by the University of Pittsburgh Institutional Review Board.

\section{Patient demographics}

In order to describe the population served, we collected basic demographic data, including: patient gender, age, education level (e.g., if the patient completed high school, completed some college or graduated from college), race/ethnicity, marital status, and annual income. We also recorded patients' smoking status, type and number of medical conditions, medications being used at baseline, and number of pharmacist visits per patient during the study review period.

\section{Medication-related problems}

For each patient, we recorded the medicationrelated problems identified by pharmacists during each visit. All medication related problems identified were defined and recorded by the pharmacists according to the classification system described by Cipolle and colleagues. ${ }^{17}$ These specific medication problem categories include: unnecessary drug therapy, needs additional drug therapy, ineffective drug therapy, dosage too low, dosage too high, adverse drug reaction, and noncompliance. The pharmacists also used one additional classification, "needs different drug product" added as an eighth categorization. As an example, a patient with type 2 diabetes currently not using an HMG Co-A reductase inhibitor but an appropriate candidate for therapy would have this problem categorized as, "needs additional drug therapy."

\section{Interventions and Clinical Data}

The number and type of pharmacist interventions made, and clinical data (hemoglobin $\mathrm{A} 1 \mathrm{C}$, blood pressure measurements, and LDL-C) for patients with diabetes, hypertension, and hyperlipidemia, respectively were recorded during the review. After each visit, pharmacists documented their interventions made as one of the following: lifestyle recommendations made (e.g., patient should exercise 30 minutes daily five or more days per week), general patient education session provided (e.g., comprehensive education on medications, disease states, etc.), education on monitoring (e.g., performing self-monitoring of blood glucose twice daily), and education on disease state (e.g., education about hypertension).

For clinical data, we recorded the last reading available within 6 months prior to implementation of the service and the last reading available postimplementation. For patients that enrolled in the program after the start of the service, we collected their first and last available readings.

\section{Cost Data}

Monthly prescription costs for each patient were estimated by taking the most recent available drug regimen from the patient's chart and pricing this regimen using May 2008 retail medication costs from www.drugstore.com. ${ }^{18}$ Any prescription drug that could be purchased at an area pharmacy offering 30 day supplies for 4 USD (an increasingly common marketing strategy in the United States) was not included in this analysis, meaning that reported cost avoidance from the perspective of the patient estimated only the savings achieved through the PMAP process.

\section{Data Analysis}

Descriptive statistics (e.g., mean and ranges) were calculated for all data. We did not aim to assess the significance of any differences as the sample sizes available for each outcome measure were small.

\section{RESULTS}

\section{Patient data}

Patient demographics are summarized in Table 1. The majority of patients served were male, middleaged, and African-American. The majority (90\%) of patients served had an income below $150 \%$ of the 2007 Federal poverty level. ${ }^{19}$ Patients were most commonly treated for diabetes, hypertension, and hyperlipidemia. A total of 100 patients were provided care by pharmacists, with patients averaging 6 visits during the study period.

During the time period we reviewed, 188 medication related problems were identified and documented by pharmacists. These are summarized in Table 2 . Noncompliance was the most common medication related problem identified, accounting for over half 
of all documented medication related problems. Of the 104 medication related problems classified as noncompliance, 69 (66\%) were because the medication was too expensive and $32(31 \%)$ were due to patient concern/patient forgets or prefers not to take the medication. "Needs additional drug therapy" was also a common problem identified.
Common pharmacist interventions included the preparation and submission of PMAP applications $(n=477)$. Other interventions included 54 documented lifestyle recommendations, 118 general patient education sessions, 48 occurrences of education on monitoring, and 62 occurrences of education on patient disease states.

\begin{tabular}{|c|c|c|}
\hline Patient demographics & & $\begin{array}{c}\text { Number of } \\
\text { evaluable patients }\end{array}$ \\
\hline Age in Years, mean (range) & $49.2(19-66)$ & $n=100$ \\
\hline Gender, \# (\%) & & $\mathrm{n}=100$ \\
\hline Men & $67(67)$ & \\
\hline Women & $33(33)$ & \\
\hline Race/Ethnicity, \# (\%) & & $\mathrm{n}=83$ \\
\hline Caucasian & $32(39)$ & \\
\hline African-American & $37(45)$ & \\
\hline Hispanic & $12(14)$ & \\
\hline Other & $2(2)$ & \\
\hline Highest Education, \# (\%) & & $n=47$ \\
\hline High School or less & $32(68)$ & \\
\hline Some College & $12(26)$ & \\
\hline Bachelor's Degree & $3(6)$ & \\
\hline Monthly Income in US \$, mean (range) & $693(0-3561)$ & $\mathrm{n}=84$ \\
\hline Patients Without Prescription Drug Coverage, \# (\%) & $84(91)$ & $\mathrm{n}=92$ \\
\hline Number of Medical Conditions, mean (range) & $2.7(1-9)$ & $n=99$ \\
\hline Common Medical Conditions, \# (\%) & & $n=99$ \\
\hline Diabetes & $74(74)$ & \\
\hline Hypertension & $54(54)$ & \\
\hline Hyperlipidemia & $29(29)$ & \\
\hline Asthma & $9(9)$ & \\
\hline GERD & $9(9)$ & \\
\hline Number of Medications, mean (range) & $5(1-16)$ & $\mathrm{n}=100$ \\
\hline Smokers, \# (\%) & $40(44)$ & $\mathrm{n}=91$ \\
\hline Marital Status, \# (\%) & & $n=91$ \\
\hline Married & $21(23)$ & \\
\hline Divorced & $5(5)$ & \\
\hline Separated & $3(3)$ & \\
\hline Single & $57(63)$ & \\
\hline Single-living with partner & $3(3)$ & \\
\hline
\end{tabular}

\begin{tabular}{|c|c|}
\hline Medication related problem, $\mathrm{n}=188$ & \# (\%) \\
\hline Unnecessary drug therapy & $15(8)$ \\
\hline Needs additional drug therapy & $43(23)$ \\
\hline Ineffective drug therapy & $0(0)$ \\
\hline Dosage too low & $13(7)$ \\
\hline Dosage too high & $3(2)$ \\
\hline Adverse drug reaction & $7(4)$ \\
\hline Noncompliance & $104(55)$ \\
\hline Needs different drug product & $3(2)$ \\
\hline
\end{tabular}

\section{Clinical indicators}

We were able to obtain at least two $\mathrm{A} 1 \mathrm{C}$ readings for 24 of 74 patients with diabetes that were seen by pharmacists during the study period, A1C levels decreased by an average of $1.2 \%$ (from $10.3 \%$ at baseline to $9.1 \%$ ). Of the 54 patients on treatment for hypertension, 42 had at least two blood pressure readings recorded during the study period. Both systolic and diastolic measurements decreased over the study period, by $2.7 \mathrm{mmHg}$ and $2.7 \mathrm{mmHg}$ respectively (from $137 / 85 \mathrm{mmHg}$ at baseline to $135 / 83 \mathrm{mmHg}$ ). For 4 of 29 patients with hyperlipidemia, LDL-C values decreased by an average of $16 \mathrm{mg} / \mathrm{dL}$ during the study period (from $108 \mathrm{mg} / \mathrm{dL}$ at baseline to $92 \mathrm{mg} / \mathrm{dL}$ ).

\section{Cost data}

Pharmacists completed 477 PMAP applications for 68 patients. We estimate that these interventions represented a mean value to an individual patient of 243 USD per month during the review period.

\section{DISCUSSION}

The purpose of this study was to describe a model for clinical pharmacy services and characterize the patient population served by the Grace Lamsam Pharmacy Program. This program demonstrates that the model is feasible and it is possible to provide clinical pharmacy services to an underserved population in safety-net provider settings. Potential dollar savings for individuals was similar to savings described by other programs that have assisted patients by using PMAPs. ${ }^{20}$

There is also the potential that the service supports improvement in clinical indicators. Blood pressure, $A 1 C$ and $L D L-C$ readings improved in patients enrolled in the program at the free clinic and the community health center. Although we believe these clinical results are relevant, statistical significance 
was not evaluated because of the small sample size.

The most common medication related problem in our patient population was noncompliance (55\%) with the most common reason for noncompliance being the cost of medications (66\%). Our population had an average household income of 693 USD per month and data suggests medication refill adherence is significantly lower in populations with low socioeconomic status. ${ }^{21}$ Pharmacists must be prepared to face these challenges in order to optimize drug therapy as studies show improved compliance when PMAP services are available. ${ }^{22,23}$ On-site clinical pharmacy services potentially enhance access for this vulnerable population.

Other factors to consider include the fact that $78 \%$ of patients using the service reported being either single, divorced or separated. Compliance is 1.74 times higher in patients from cohesive families and marital status increases compliance. ${ }^{24}$ Although a majority of the medication related problems reported as noncompliance in this study were due to cost, future studies assessing the impact of pharmacy services on compliance are needed.

There are many challenges to evaluating the success of this service. One of the challenges in doing this evaluation is the limited availability of laboratory data. Access to this service is a barrier for various reasons. For example, although lab tests are available for free at a local community hospital, some patients are still unable to obtain these tests due to barriers such as transportation.

Although clinical indicators appeared to improve for this population during the period of review, a cause and effect relationship between clinical pharmacy services provided and improvement in clinical indicators could not be established without a control population. Further, statistical comparisons were not made as data are limited. Future studies using control groups and statistical comparisons are needed to determine the extent that clinical changes can be attributed to pharmacy services.

\section{CONCLUSIONS}

A clinical pharmacy services model provides a role for the pharmacist in an interdisciplinary team (beyond the traditional dispensing role) to identify medication related problems in the drug therapy of patients who utilize safety-net provider health care services.

\section{CONFLICT OF INTEREST}

Authors declare no conflict of interest.

\section{References}

1. U.S. Department of Health and Human Services. Healthy People 2010: understanding and improving health. 2nd ed. Washington, DC: U.S. Government Printing Office; 2000.

2. Smedley BD, Stith AY, Nelson AR, eds. Unequal treatment: confronting racial and ethnic disparities in healthcare. Washington, DC: The National Academies Press; 2003.

3. Centers for Disease Control. Health insurance coverage: early release of estimates from the National Health Interview Survey, 2006. http://www.cdc.gov/nchs/data/nhis/earlyrelease/insur200706.pdf (accessed 2008 May).

4. Kennedy J, Coyne J, Sclar D. Drug affordability and prescription noncompliance in the United States: 1997-2002. Clin Ther. 2004;25:607-614.

5. Economic problems facing families. The Kaiser Family Foundation Public Opinion Survey Brief April 2008. http://www.kff.org/kaiserpolls/upload/7773.pdf (accessed 2008 December).

6. Mullins CD, Blatt L, Gbarayor CM, Yang HW, Baquet C. Health disparities: a barrier to high quality care. Am J Health-Syst Pharm. 2005;62:1873-1882.

7. Koecheler JA, Abramowitz PW, Swin SE, Daniels CE. Indicators for the selection of ambulatory patients who warrant pharmacist monitoring. Am J Health-Syst Pharm. 1989;46:729-732.

8. Ferenchick GS. The medical problems of homeless patients: a comparative study. J Gen Intern Med. 1992;7:294-297.

9. Brown CM, Barner JC, Shepard MD. Issues and barriers related to the provision of pharmaceutical care in community health centers and migrant health centers. J Am Pharm Assoc. 2003;43:75-77.

10. Shane-McWhorter, L, Oderda, GM. Providing diabetes education and care to underserved patients in a collaborative practice at a Utah community health center. Pharmacotherapy. 2005;25(1):96-109.

11. Leal S, Glover JJ, Herrier RN, Felix A. Improving quality of care in diabetes through a comprehensive pharmacist-based disease management program. Diabetes Care. 2004;27:2983-2984.

12. Scott DM, Boyd ST, Stephan M, Augustine SC, Reardon TP. Outcomes of pharmacist-managed diabetes care services in a community health center. Am J Health-Syst Pharm. 2006;63:2116-2122.

13. Caballero J, Souffrant G, Heffernan E. Development and outcomes of a psychiatric pharmacy clinic for indigent patients. Am J Health-Syst Pharm. 2008;65:229-233.

14. Centers for Medicare and Medicaid Services. Medicare Prescription Drug Benefit Final Rule. Federal Register., vol. 70 , no.18. January $28,2005$.

http://www.pharmacist.com/AM/Template.cfm?Section=Home2\&TEMPLATE=/CM/ContentDisplay.cfm\&CONTENTID=4 131 (accessed Dec 2008).

15. American Pharmacists Association, National Association of Chain Drug Stores Foundation. Medication therapy management in pharmacy practice: core elements of an MTM service model. Version 2.0. J Am Pharm Assoc. 2008; 48: 341-353. 
16. McGivney MS, Meyer SM, Duncan-Hewitt W, Hall DL, Goode JR, Smith RB. Medication therapy management: its relationship to patient counseling, disease management and pharmaceutical care. J Am Pharm Assoc. 2007;47:620628.

17. Cipolle, RJ, Strand, LM, Morley, PC. Pharmaceutical Care Practice: The Clinician's Guide. 2nd ed. New York: McGrawHill;2004.

18. http://www.drugstore.com/ (accessed April 2008).

19. Federal Register: January 24, 2007;72(15):3147-8 From the Federal Register Online via GPO Access [wais.access.gpo.gov](DOCID:fr24ja07-74) (accessed May 2008).

20. Chisolm, MA, Spivey CA, Mulloy LL. Effects of a medication assistance program with medication therapy management on the health of renal transplant recipients. Am J Health-Syst Pharm. 2007;(64):1506-1512.

21. Schectman JM, Bovbjerg VE, Voss JD. Predictors of medication-refill adherence in an indigent rural population. Med Care. 2002;40:1294-1300.

22. Dent LA, Stratton TP, Cochran GA. Establishing an on-site pharmacy in a community health center to help indigent patients access medications and improve care. J Am Pharm Assoc. 2002;42:497-507.

23. Schoen M, DiDomenico R, Connor S, Dischler J, Bauman J. Impact of the cost of prescription drugs on clinical outcomes in indigent patients with heart disease. Pharmacotherapy. 2001; 21:1455-1463.

24. DiMatteo MR. Social support and patient adherence to medical treatment: a meta-analysis. Health Psychology. 2004;23:207-218.

\section{Welcome to Lisboa!}
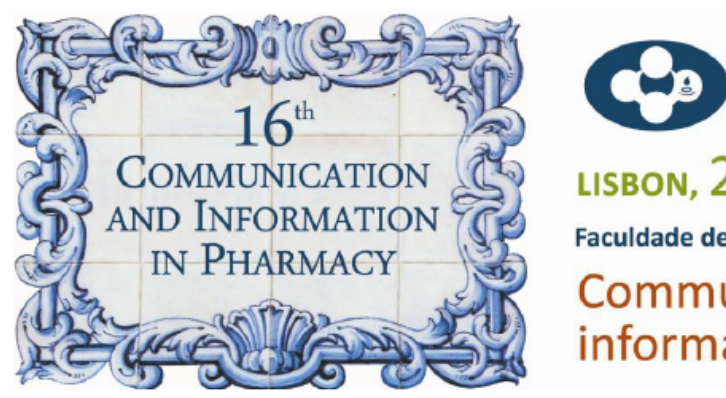

LISBON, $23^{\text {rd } / 26 \text { th }}$ AUGUST 2010

Faculdade de Farmácia da Universidade de Lisboa

Communication and information in pharmacy

This is a preliminary short announcement for the $16^{\text {th }}$ ISPW

$$
\begin{aligned}
& \text { Host Institution and Venue } \\
& \text { Faculty of Pharmacy, University of Lisbon, Portugal } \\
& \text { Dates } \\
& 23^{\text {rd }} \text { to } 26^{\text {th }} \text { August } 2010
\end{aligned}
$$

Key note Speakers and further information soon to be announced at Www.ff.ul.pt/16ISPW

For any inquiries, please use the following email address: $16 \mid$ SPW@ff.ul.pt

Hope to have you here in Summer 2010! 